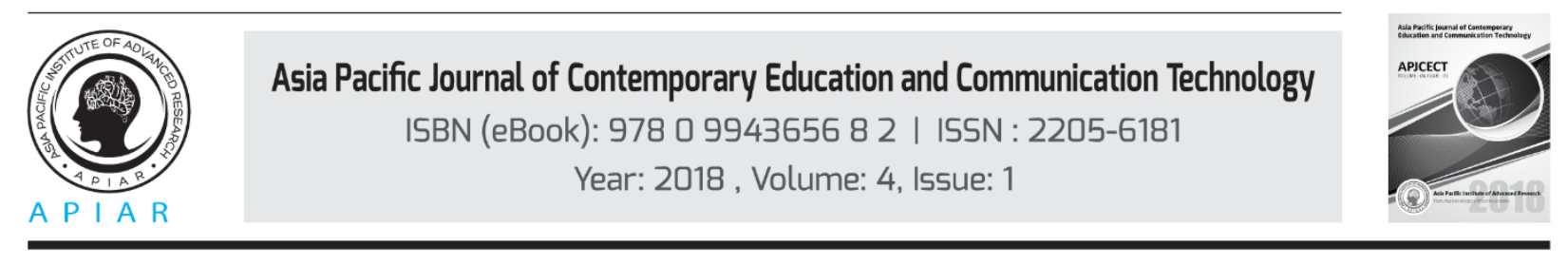

\title{
ON THE USE OF THE MACD TO PREDICT POWER PRODUCTION AND HERS SIZING
}

\author{
Azzouz Benlahouar a Mohammed Bougataya ${ }^{\mathrm{b}}$ \\ abc University of Quebec in Outaouais, Gatineau Canada \\ Corresponding email: bena73 @uqo.ca
}

\begin{abstract}
This paper proposes a new method related to efficient instantaneous prediction in order that the installed power generation capacity meets the load demand, by analysing the historical power demand. The proposed method is based on moving average convergence divergence (MACD) to predict the power demand instantaneously from the last and present demand. This approach was used for dispatching an optimal PV/WT/Batteries renewable power generation. This method was implemented and simulated in Matlab environment and shows promoted performances.
\end{abstract}

Keywords: MACD, Renewable energy, Energy production management, Prediction, Power load, Sizing.

\section{Introduction}

The main components of a traditional electricity system are four main sectors: generation, distribution, bulk transmission and consumption (Strbac, 2008). These four sectors are linked in order to supply demand that varies daily and seasonally. The system has to fulfill the uncontrollable demand and also avoid costly interruptions. In addition, the installed generation capacity must be able to meet the maximum (peak) demand. Unfortunately, electricity demand is very inflexible, especially in the short term. It is also unlikely in the near future to store electricity on large scale (Yang \& Chen, 2009).

To allocate optimal power generation between different units, an accurate prediction of the future available solar and wind energy resources is necessary. Hence, significant meteorological variables decide the attainable energy from renewable resources. A good management of energy demand may allow better utilization of resources without waste and without interruption of provisions. The output of the different sources of renewable energy varies with weather conditions and it is not possible all the time to modulate renewable to follow a desirable demand shape. However, load demand is expected to take a more active role in matching the electricity production and the demand-side management which is in crucial guaranteeing a stable and efficient operation system (Wang, et al., 2015).

The evolution of the electricity generation industry in the last decade has been so rapidly that it is now possible integrating the hybrid system to renewable energy sources on the same platform. This move towards integration levels higher is motivated by the needs of increasingly efficient systems, consequently producing huge electrical energy. However, this has created new problems that are related to the optimal management of electricity production from renewable Asia Pacific Institute of Advanced Research (APIAR) 10.25275/apjcectv4i1ict6 
sources. The design process associated with these systems is a relatively complex, since it implies the need to consider both the operating strategies and dimensioning of components for different system configurations. In addition, constraints and opportunities unique to each project must be taken into account.

Autonomous hybrid power systems have experienced extensive use in most sectors. The installation of such a system requires the study of its component configuration and management. Several authors have been interested to study the modelling, control and optimization of hybrid energy systems from design to operation.

In paper Ekren \& Ekren (2008) the authors used the response surface methodology (RSM) in size optimization of an autonomous PV/wind integrated hybrid energy system with battery storage. This method aims to decrease the number of experiments, time, and material resources.

An optimum sizing tool Yang, et al., (2009) for hybrid solar-wind systems employing a battery bank, is developed based on the loss of power supply probability. In this study an optimum combination of a hybrid solar wind energy system has be achieved to satisfy both the reliable and economical requirements. An economic approach based on the concept of the Levelized Cost of Energy, is developed to be the best benchmark of cost analysis in this study. In paper Abbes, et al., (2011) the authors proposed a new approach for sizing hybrid systems, based on system Life Cycle Analysis in terms of Embodied Energy (EE: energy required by all the activities associated to a production process expressed on MJ or $\mathrm{kWh}$ ). EE and LPSP are used to optimize the best configuration of wind turbine rotor area, installed PV generator and batteries capacity.

Kellogg, et al., (1998) the authors adopted an iterative method of optimization based on which the accumulative energy generated from wind and solar energy will balance the total demand while the variations in the demand profile are offset by other sources, such as a backup diesel generator or battery storage. In Wang, et al., (2015) the authors has modified and upgraded this approach and adopted Receding Horizon Optimization (RHO) in which a certain cost function is minimized over an effect time-horizon to determine the optimal power references for the various energy generation subsystems.

A preliminary estimation of electricity consumption for the future can be perfectly generated as a coordinated effort between the electricity supplies and users. Usually, the electricity providers are interested to know the consumption ahead of time. In Nolde \& Morar, (2010) the authors proposed to the consumer scheduling his production processes to meet load schedules accordingly. As a continuation in this study we propose, in this paper, an HRES configuration composed by PV panel, wind turbine and batteries for storage.

This paper is organized as follow: In Section I, the architecture and the modeling of the HRES. Section II, we propose a new approach of power prediction, the MACD-indicator based temporal power demand prediction algorithm is described. Section III, the simulation (By using Matlab) result are reported and section IV is conclusion of the paper.

\section{Architecture and Modeling Hybrid System Energy 2.1 General Architecture}

This sizing approach is a modification of the method proposed by Wang et al. (2015), based on which the accumulative energy generated from the wind turbine system and solar system will 


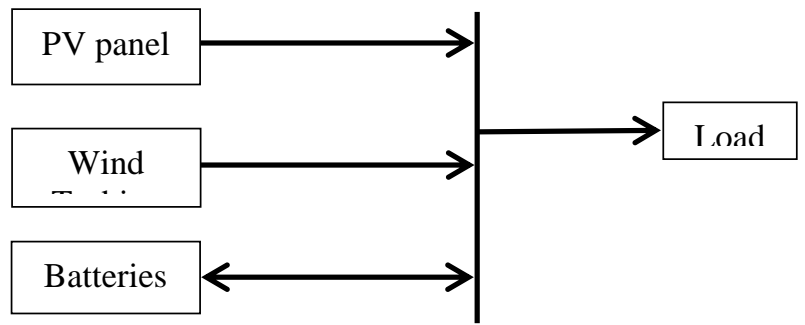

Figure 1: General HERS architecture.

balance the total demand while the variation in the demand profile are compensated by a backup battery storage.

Figure 1 is the general architecture of HERS system used in this research. Three different units of the HERS are shown in this figure: PV panel, wind turbine, and batteries. The optimal power generation dispatching is given by the following stages:

Step1. Select available commercial PV panel, wind turbine and battery storage Step 2. Use historical power demand data to predict the power demand.

Step 3. Use the weather forecast to determine the best option.

Step 4. Balanced power guaranteed by the battery units.

Step 5. Determine the optimal HRES.

The algorithm presented in Figure 2 was simulated and implemented in Matlab environment.

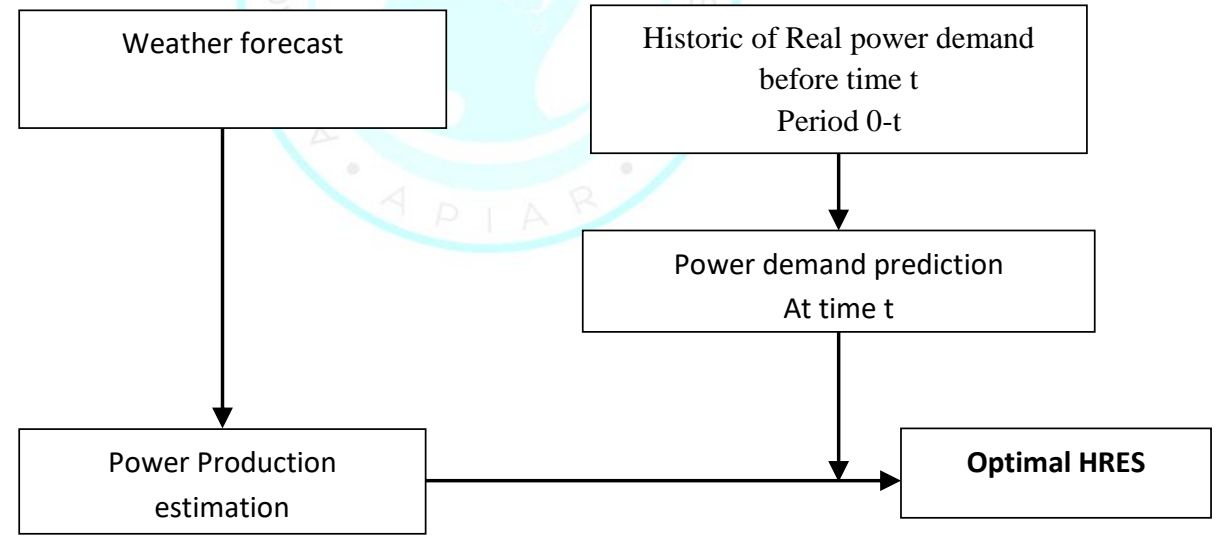

Figure 2: Procedure for optimal dispatching of the power generation.

\subsection{Modeling of the PV Generator}

The performance of photovoltaic modules depends on several parameters, namely, the irradiation, the temperature and the load to be supplied. We assume that the PV system is controlled by an MPPT command to maximize the output power. Hence, a simple model of PV was used to calculate the generated power of the PV system [IX-X]:

$A$ (in $m^{2}$ ): Solar panel area

$$
P_{P V}=A \times r \times I_{r} \times \rho
$$
$r$ : Solar panel yield 
$\operatorname{Ir}\left(\right.$ in $\left.W / m^{2}\right)$ : Solar radiation

$\rho$ : Performance ratio (between 0.5 and 0.9 )

Keep line spacing at 1. Font type is Georgia. Font size is 11pt. Please do not alter the formatting and style layouts which have been set up in this template document. Do not indent the first paragraph in each section. Keep line spacing at 1. Font type is Georgia. Font size is 11pt. Please do not alter the formatting and style layouts which have been set up in this template document. Do not indent the first paragraph in each section.

\subsection{Modeling of Wind Generator}

The wind generator is characterized by its power curve which depends on the speed of the available wind. Assuming that the wind turbine operates in maximum power operating point MPPT mode, a simple model can simulate the output power as follows (Bogdan et al. 1994):

$$
P_{w}=\left\{\begin{array}{cl}
P_{\text {rat }} \times \frac{v^{k}-v_{\text {in }}}{v_{\text {rat }}-v_{\text {in }}}, & v_{\text {in }} \leq v \leq v_{\text {rat }} \\
P_{\text {rat }} & v_{\text {rat }} \leq v \leq v_{\text {out }} \\
0 & \text { otherwise }
\end{array}\right.
$$

The power output characteristic can be assumed in such a way that it starts generating at the cut-in wind speed vin, the power output increases linearly (in some study is not linear) as the wind speed increases from $v_{\text {in }}$ to the rated wind speed $v_{\text {rat. }}$. The rated power $P_{\text {rat }}$ is reached when the wind speed varies from $v_{\text {rat }}$ to the cut-out wind speed $v_{\text {out }}$ at which the wind electrical conversion system will be shut down for safety.

The energy curve is specified over the range of 3 to $15 \mathrm{~m} / \mathrm{s}$ annual average wind speed and typical graphical display is shown in fig.4.

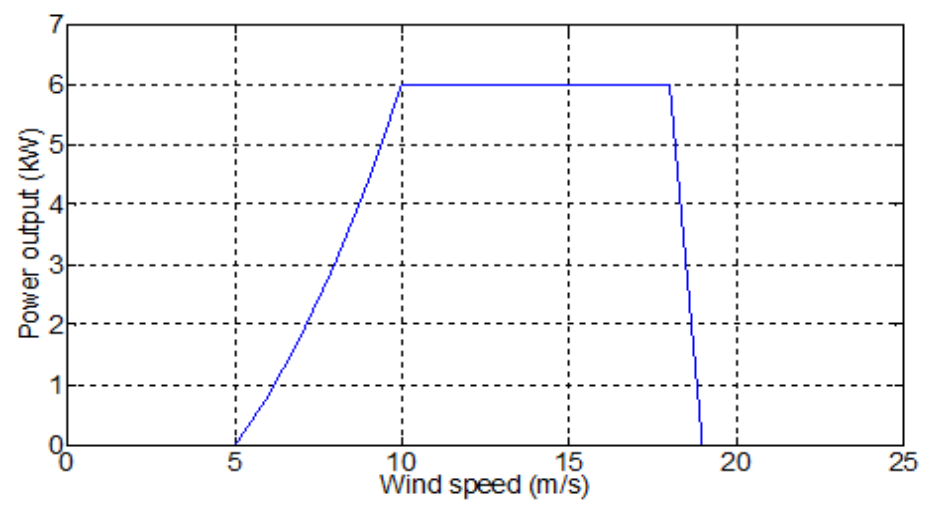

Figure 3: Typical graphical wind turbine power curve

\subsection{Storage Characteristics}

In this study, batteries back-up is implemented to meet the load demand during non-availability period of renewable energy source. In general battery has 2 or 3 days of autonomy. The maximum capacity of the batteries is limited. No over-discharging is allowed in order to extend the lifetime of the batteries. Storage is empty at the beginning of the simulation and will be charged when the power demanded by the load will be less than that produced by the hybrid Asia Pacific Institute of Advanced Research (APIAR)

10.25275/apjcectv4i1ict6 
system. In the opposite case, the storage will cover the unmet power if sufficient energy is available in storage. The battery storage have be sized to operational optimization and load to be satisfied It is considered here that the hybrid system will satisfy a consumption which the profile is the actual consumption of a single house. The consumption profile has been measured every 2 min for a period between December and March. The variation of the load during a day is shown in Figure 9. In this study the hybrid system has to work offline when the entire load is satisfied while it must work in parallel mode with the electric network only for fulfill the unmet power demand.

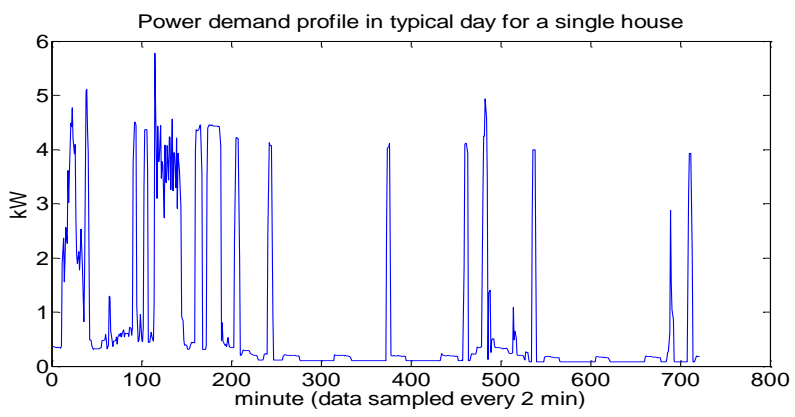

Figure 4: Real-time forecasting of weather data

Wind and solar irradiation are intermittent; only the weather forecast data can provide such information on available energy for demand dispatch. An accurate prediction of the available future solar and wind energy resources is primordial to optimally distribute electricity generation among the different HERS system's units.

Different statistical approaches such as: auto-regression, integrate moving average, neural networks etc. can be used to forecast wind speed and solar irradiance.

In this work, solar and temperature data of historical, current conditions and forecasts are obtained from [XVII].

\section{Power Demand Side Management. 3.1 Moving Average Convergence/Divergence (MACD)}

Moving Average Convergence/Divergence (MACD) was developed by Gerald Appel in the late seventies. MACD oscillator is one of the simplest and most effective momentum indicator. The MACD turns two indicators, moving averages, into a momentum oscillator by subtracting the longer moving average from the shorter moving average. MACD of a data set is calculated by subtracting two Exponential Moving Average (EMA) corresponding to the, two different periods. First EMA is calculated for a short period (p3) and the second one is called EMA for a long term period (p2). Figure shows an example of MACD chart. MACD Figure 5 is obtained from the plotted data set series in Figure 7.

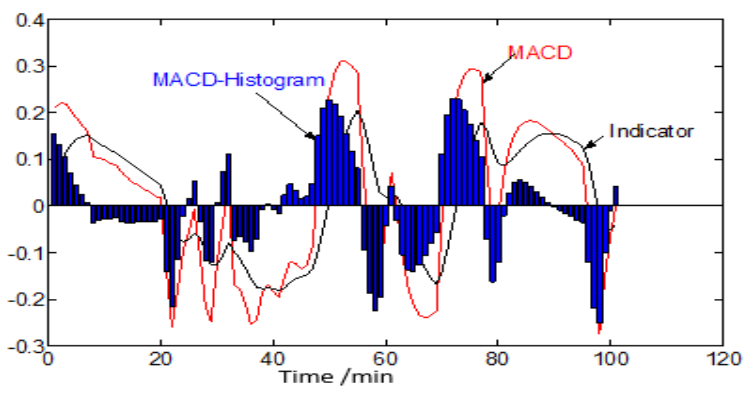

Figure 5: MACD-Histogram and MACD Indicator 


\subsection{Calculation}

The MACD Line is the subtraction of the 18-min EMA and 24-min EMA. A 18-min EMA of the MACD is plotted with the indicator to act as a signal line and identify turns. The MACD Histogram represents the difference between MACD and its 12-min EMA. The histogram is positive when the MACD Line is above its Signal Line and negative when the MACD Line is below its Signal Line Figure 6.

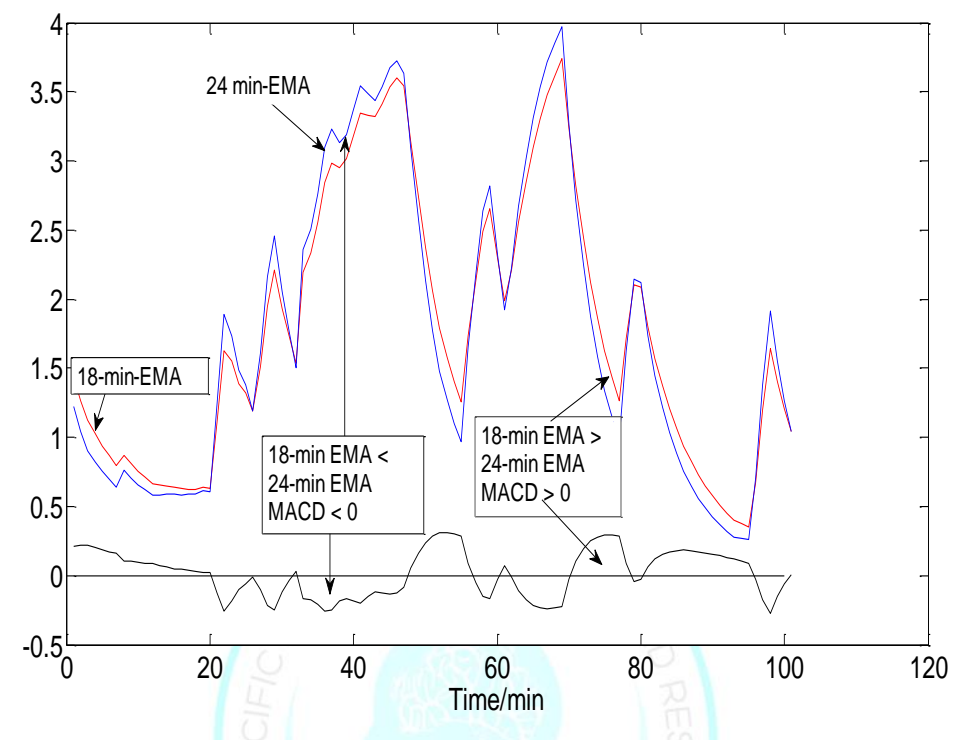

Figure 6: Sample of MACD plot

\section{Proposed Algorithm for Power Demand Prediction}

The electricity providers are always interested in knowing in advance the consumption ahead of time. Despite, it is not possible in all cases. In this paper, we propose an alternative way by estimating and predicting the future power demand. This method is based on the behaviour of the customer consumption during a short term. To apply this method, we consider the consumption for the last $60 \mathrm{~min}$ as adequate short period of time. Also, in this study, we consider the residential electricity demand of a single-family house by summing up all the active appliances at each time.

From a measured electricity consumption $\left\{d_{i}\right\}_{i=0: T:(t-1) x T}$ during a certain interval of time varying from zero to $(t-1) x T$ predict the $\mathrm{di}=\left(\mathrm{t}^{*} \mathrm{~T}\right) \mathrm{T}$ minute a head.

$\frac{1}{T}$ : Frequency of sampling the data.

The proposed algorithm is:

1. Choose a data sampled every $\mathrm{T}$ of unit time.

2. Calculate MACD of $D_{N-1}=\left\{d_{i}\right\}_{i=0: T:(N-1) x T}$ : MACD1

3. Calculate the MACD of $D_{N}=\left\{D_{N-1}, S_{n}\right\}$ for different value of $S_{n}$ : MACD2 $S_{n}=$ Initiaal value $+n \times \Delta d$

4. Compare MACD2 Indicator at time $t=n x T$ to MACD1 indicator at time $t=(n-1) x T$. 
The comparaison of the MACDs is based on the following Hypothesis:

For a short time (duration T), MACD can undergo a slight variation.In other term MACD indicator of the data set of the power demand during a period $(\mathrm{N}-1) \mathrm{xT}$ is constant after $\mathrm{T}$ min or has a smaller variation as $\varepsilon$ given in Eq.8 .

$$
\begin{gathered}
\text { MACD1 }=\left\{\operatorname{macd}_{i}\right\}_{i=1: T:(N-1) x T} \\
M A C D 2=\left\{\operatorname{macd}_{i}\right\}_{i=1: T: N T} \\
\|M A C D 1(t=N T)-M A C D 2(t=(N-1) T)\| \leq \varepsilon
\end{gathered}
$$

MACD1 is the MACD indicator obtained from data set of $\mathrm{N}-1$ measurements. The value of power at time $t=\mathrm{N}^{*} \mathrm{~T}$ is the future value of power demand. MACD2 is the MACD indicator obtained from the data set of $\mathrm{N}$ measurements.

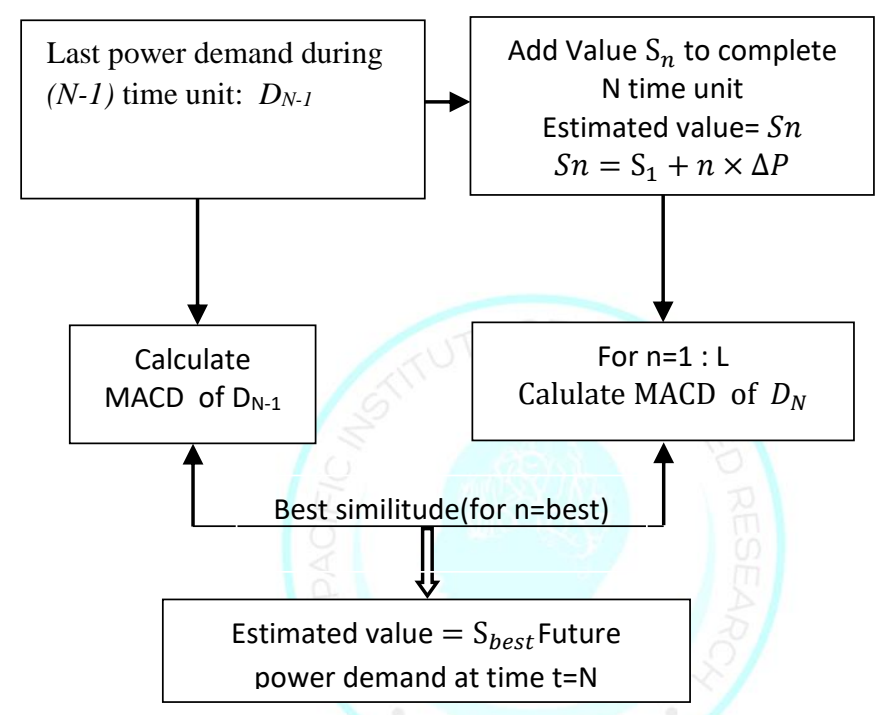

Figure 6: Algorithm using power demand profile and MACD to predict power load

In this algorithm we use profile demand of a single house Fig.9. This profile is divided into L states of power.

The choice of energy demand is restricted only to these $L$ states $(S n ; n=1: L)$. By applying the proposed algorithm one state will be retained and will be considered as the value of energy demand at time $t=N$. The value of the indicator at time $t=\mathrm{N}-1$ will be used as a reference to determine the power demand at time $t=N$. The MACD of the profile of energy demand during the period $\mathrm{N}-1$ will decide to determine the turns in demand and will allow to evaluate the power load for the future (next T minutes) .

Limit and strictness are two important parameters that define the range of power demand. For example if Limit is 1000 and strictness to 0.2. Hence, the power demand range is $0.0364 \mathrm{~kW}$ $200 \mathrm{~kW}$.

Fig. shows the profile of the power consumption, the maximum of power demand is 115.9965 $\mathrm{kW}$ and the minimum is $0.0364 \mathrm{~kW}$.

$$
S_{i+1}=S_{i}+\Delta P
$$

$\Delta P$ is increment of energy. 


\section{Simulation and Result}

To illustrate the performance of our proposed algorithm we used the residential electricity consumption collected for every 2 min from October to march. Figure 8 shows the consumption on spring day in a single family house. From the chosen measured consumption of power DN-1 presented in Figure 9 we need to predict the value of the power consumption after 2 min. the value of MACD at time $t=60 \mathrm{~min}$ is -0.0642 . This can be used as a reference to find the next power consumption at time $t=62 \mathrm{~min}$. Using a bench of $\mathrm{DN}$ for different value of Sn MACD corresponding to different series of DN, the closed value of MACD is -0.0548 and the correspondent value of power consumption $(\mathrm{Sn})$ is $1.1083 \mathrm{~kW}$, while the measured value is $0.9047 \mathrm{~kW}$.

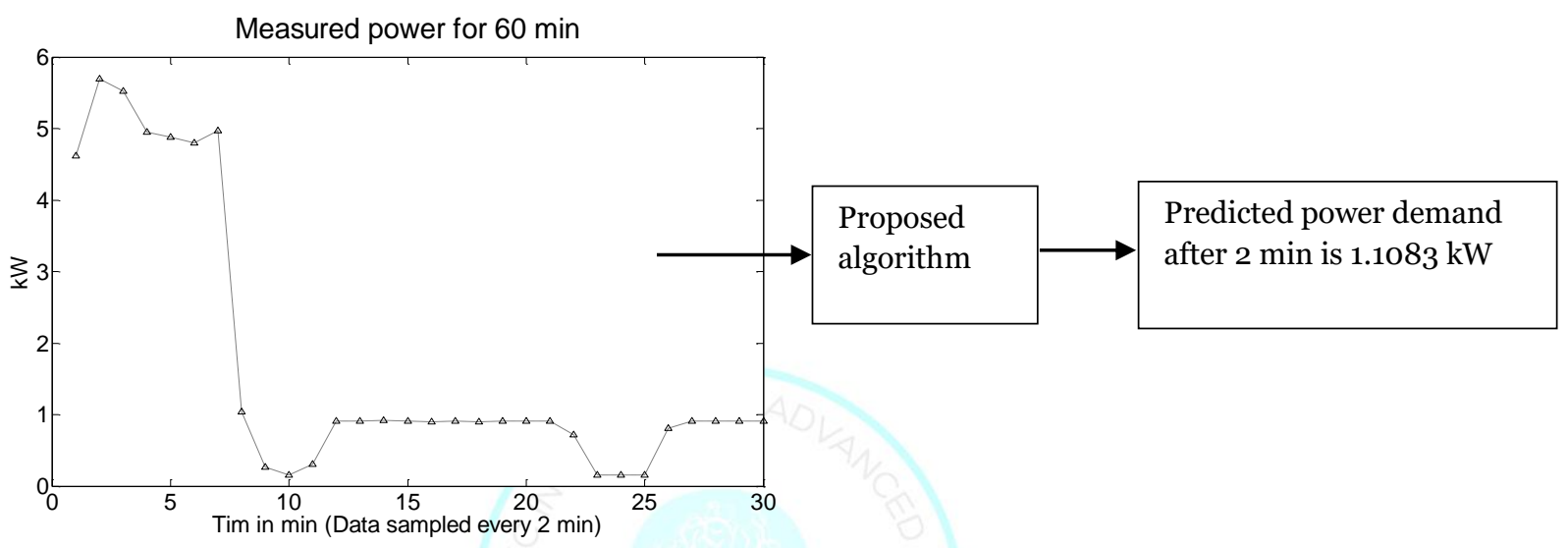

Figure 7: Example of used past power to predict the next demand power after 2min.

Using another different set $\mathrm{D}_{\mathrm{N}}$ of power demand profile the predicted power demand for the next $44 \mathrm{~min}$ is presented in the figure 10.
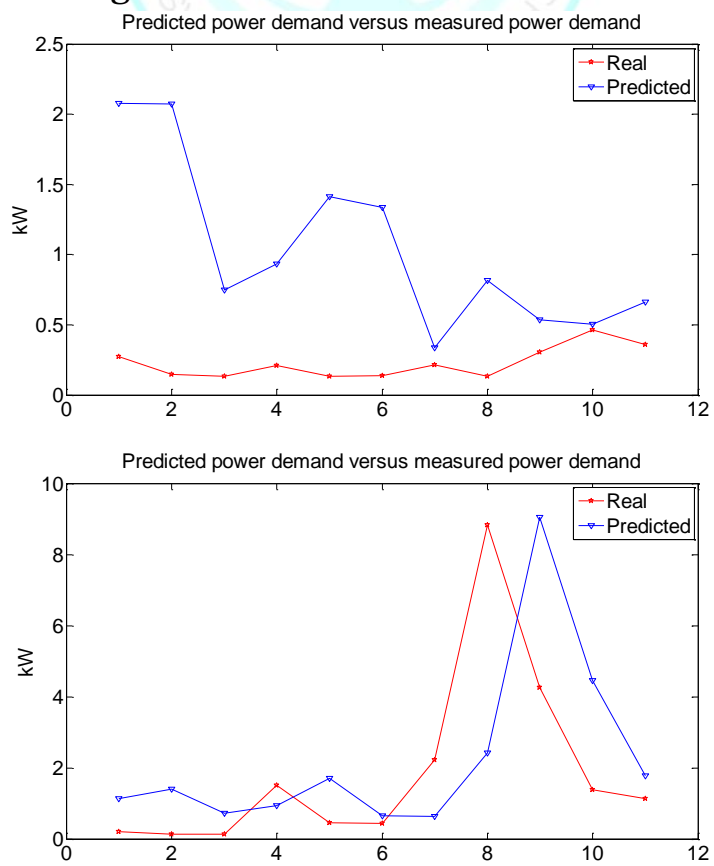


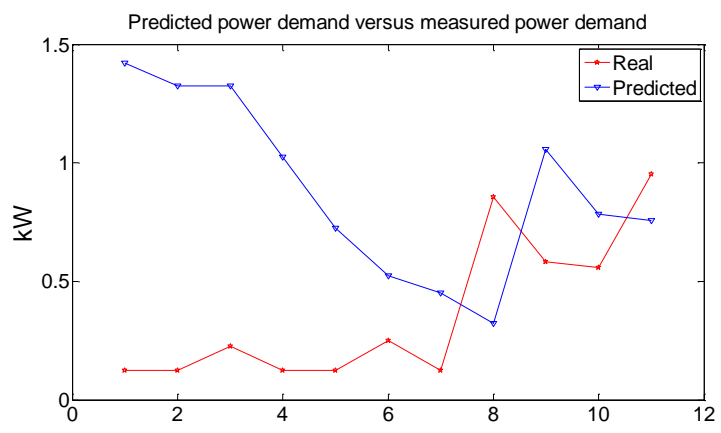

Figure 8: Using different $\mathrm{D}_{\mathrm{N}-1}$ to predict the power demand

Figure 9 Shows the predicted values obtained by the proposed algorithm using different DN-1 for different time of day. As we observe, the predicted values depend on the previous power demand (DN-1) for the last $60 \mathrm{~min}$. In each case we predict one value of the power demand at the time, and $\mathrm{DN}-1$ is updated by adding the real value at time $\mathrm{t}=\mathrm{N}$ and extracting the first value at time $t=1$. $D_{N-1}$ keep all the time the same length (30 measurements).

To test the performance of this algorithm we consider a bench of $50000 \mathrm{D}_{\mathrm{N}-1}$. Each $\mathrm{D}_{\mathrm{N}-1}$ data represent the power demand for different period of day (every $\mathrm{D}_{\mathrm{N}}-1$ contains 30 measurements). This big number of $\mathrm{D}_{\mathrm{N}}-1$ data allows to cover different habit of the customer consumption for different hour and for different days (24 hours). In this study we use a collected data for five months (starting from 23th, October 2012 to 1st, marsh 2013). This algorithm leads to predict the consumption at time $\mathrm{t}=\mathrm{N}$. The performance of this algorithm is calculated by comparing the predicted consumption (dN_Predicted) and the measured (dN_Measured). the performance of this algorithm is the percentage of satisfaction of equation (8).

$\varepsilon$ is positive value. Usually $\varepsilon$ varie from 0 to $3 \mathrm{~kW}$

$$
\mathrm{dN}_{\text {Predicted }}-\mathrm{dN}_{\text {Measured }}>\varepsilon
$$

Table 1: Example of procedure to find the optimal parameters.

\begin{tabular}{|c|c|c|c|c|c|c|c|c|c|}
\hline$\left(\mathrm{p}_{1}, \mathrm{p}_{2}, \mathrm{p}_{3}\right)$ & $16,12,6$ & $\begin{array}{l}6,16,1 \\
2\end{array}$ & $\begin{array}{l}8,18,1 \\
4\end{array}$ & $\begin{array}{l}10,20,1 \\
6\end{array}$ & $\begin{array}{l}36,22,1 \\
8\end{array}$ & $\begin{array}{l}48,28,2 \\
0\end{array}$ & $\begin{array}{l}36,24,1 \\
4\end{array}$ & $\begin{array}{l}28,16, \\
8\end{array}$ & $\begin{array}{l}48,18,1 \\
2\end{array}$ \\
\hline \multirow{3}{*}{$\begin{array}{l}\text { Performan } \\
\text { ce }\end{array}$} & $\begin{array}{l}\mathrm{T}=120 \mathrm{~m} \\
\text { in }\end{array}$ & 69.34 & 70.20 & 70.77 & 70.98 & 70.88 & 70.86 & 70.89 & 70.91 \\
\hline & $\begin{array}{l}\mathrm{T}=60 \\
\min \end{array}$ & 72.38 & 72.76 & 73.09 & 73.38 & 73.60 & 73.65 & 73.75 & 73.86 \\
\hline & $\mathrm{T}=2 \mathrm{~min}$ & 82.91 & 83.06 & 83.23 & 83.35 & 84.05 & 83.26 & 83.95 & 84.56 \\
\hline
\end{tabular}

Also We us big number of combination of parameters we found for a $\mathrm{N}=60$ min the best triple of $\left(\mathrm{p}_{1}, \mathrm{p}_{2}, \mathrm{p}_{3}\right)$ is $(24,18,6)$.

Table 2: Performance of the proposed algorithm using the optimal parameters.

\begin{tabular}{|l|l|l|l|l|l|l|l|l|l|l|l|}
\hline MACD, $\mathrm{p}_{1}=24, \mathrm{p}_{2}=18, \mathrm{p}_{3}=6, \quad(\mathrm{~N}-1)=60 \mathrm{~min}$ \\
\hline $\begin{array}{l}\text { Time of } \\
\text { prediction in } \\
\text { min }\end{array}$ & 500 & 240 & 120 & 60 & 50 & 40 & 30 & 20 & 10 & 4 & 2 \\
\hline Performance & 67.14 & 71.25 & 70.97 & 75.25 & 74.97 & 75.16 & 75.91 & 77.49 & 0.78 & 85.83 & 86.37 \\
\hline
\end{tabular}




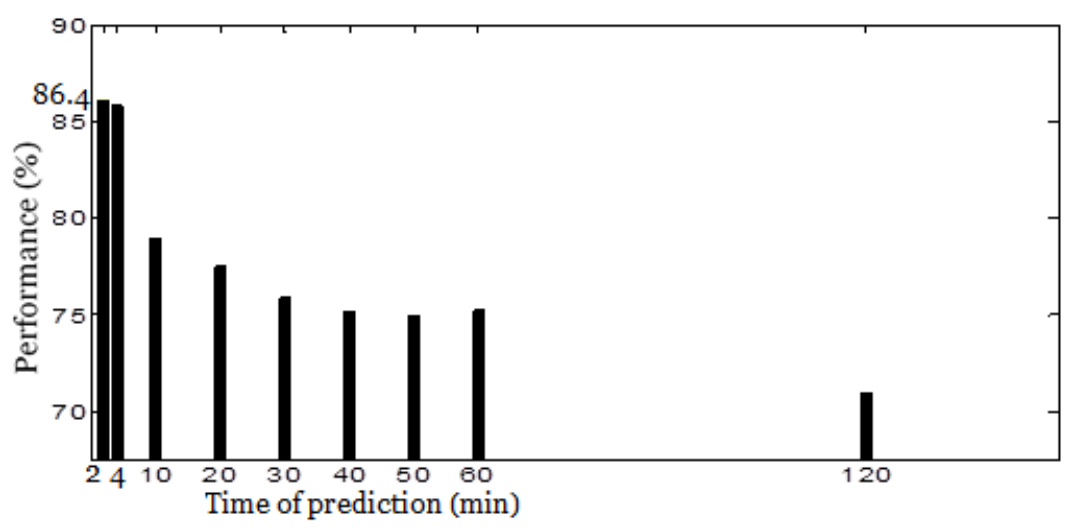

Figure 9: Performance of the proposed algorithm.

The performance of the prediction (Table 2) decreases in time ahead. As long as the time of prediction is longer as the performance decrease. The performance to predict the power $2 \mathrm{~min}$ ahead is maximum $86.37 \%$.

\section{Analysis of Result}

The optimal power production in response to the predicted power demand is given by the black dashed profile Fig.11. This optimal power fulfils most of the time the power demand. Eighty percent of time the power generation satisfies the demand power.

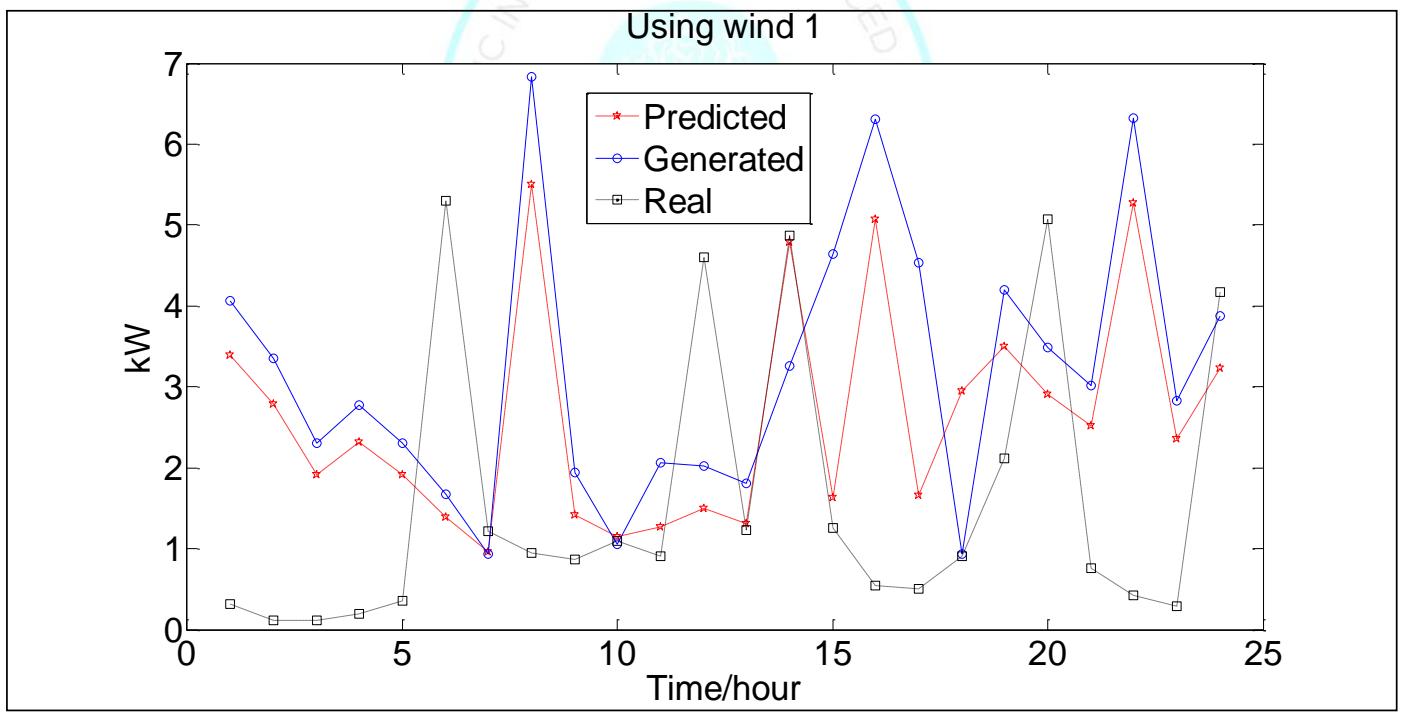

Figure 10: Optimal power production on response to predicted power demand.

This algorithm can be very interesting for houses which does not require a continuous quality electric power. It's approximately $13 \%$ of chance that the power demand prediction can cause of time.

Wind (1) characteristic: Rated output Power: 6kW, Cut-in speed $=5 \mathrm{~m} / \mathrm{s}$, Rated out speed $=10 \mathrm{~m} / \mathrm{s}$, Cut-out speed $=20 \mathrm{~m} / \mathrm{s}$.

Power generation depend on the predicted power and the weather forecast. Hence, is same cases the power generated by the HERS does not fulfil the power demand for example there is a lack of production at 6am, 12pm, $8 \mathrm{pm}$ and 12 am (figure 11). 
Figure 11 is a typical dispatching power generation on respond to the predicted power demand obtained by the proposed algorithm. This power generation is obtained regardless the coast. This power dispatching considers only the available power and combines then in the way fulfils the power demand.

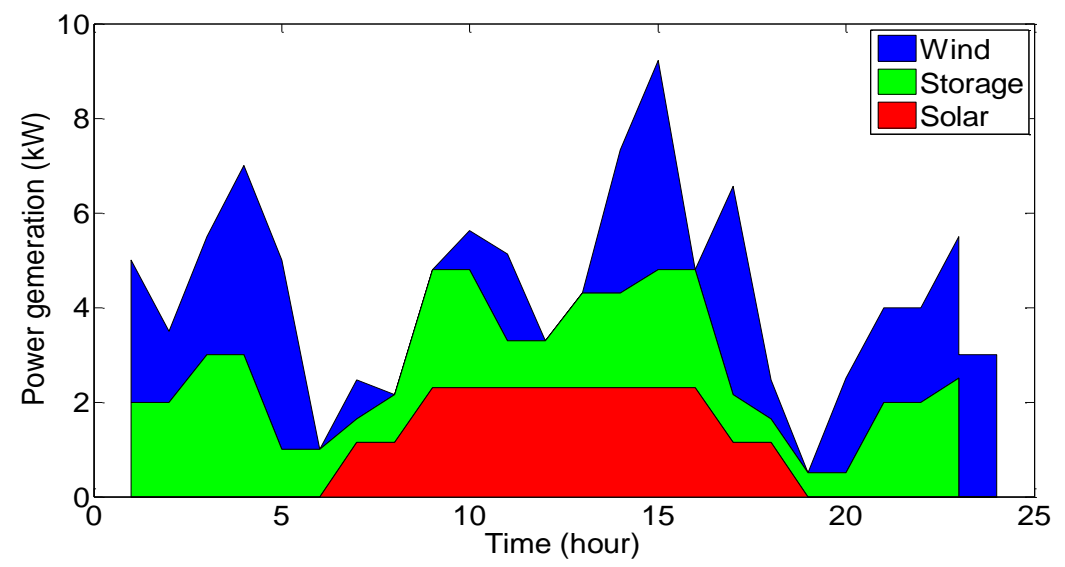

Figure 11: Optimal generation profile for a typical day considering predicted demand and on line-forecasting.

The study shows that it is impossible to completely satisfy a load with a hybrid system without adding an adequate storage device. The optimal dispatching power obtained in Figure 11 is according to the operating optimization depends strongly on the site of the energy potential installation and specifically the temporal and energy distribution of resources. Despite the fact that the habit of the human consumer can be never predicted perfectly, the methods adopted in this article can be improved in several ways: improving strategies to control sources of energy, adding more storage devices, taking into account other criteria including economic etc.

\section{Conclusion}

In this paper a power demand of every 2 min was used as a reference to predict the power demand 2 min a head. An MACD approach has been proposed to predict the power load of one single house. The result show that the proposed predicting algorithm is able to predict (in $86 \%$ of time) instantaneously ( 2 min ahead) power load according to the past ( 1 hour before) and present load. Based on the actual power consumption, the prediction approach was developed using MACD and the hypothesis 'For a short time, MACD can undergo a slight variation'.

We found that the MACD indicator is very useful to help electricity producer and to identify various information, especially with the possibility to notice consumption changes very early. For the optimal EMA a short period $18 \mathrm{~min}$ and long term period of $24 \mathrm{~min}$, the performance of the proposed algorithm show a very good performance to predict power consumption in short term as $2 \mathrm{~min}$ and in a long term as $500 \mathrm{~min}$. This kind of prediction can be useful for real time management of power demand production. Therefore, it is an important indicator, it is necessary to refine the strategy or approach used, with additional means for determining the variation in power consummation in long term and avoiding lack of production. 


\section{References}

i. $\quad$ Abbes, D., Martinez, A. \& Champenois, G., 2011. Eco-design Optimisation of autonomous hybrid wind-photovoltaic system with battery storage, s.l.: s.n.

ii. Borowy, B. S. \& Salameh, Z. M., 1994. Optimum Photovoltaic Array Size for a Hybrid Wind/PV System. IEEE Transactions on Energy Conversion, 9(3).

iii. Bourdoucen \& Gastli, A., 2008. Tuning of PV array layout configurations for maximum power delivery. Int. J. Electr. Inf. Eng, 2(4), p. 211-217.

iv. Ekren, O. \& Ekren, B. Y., 2008. Size optimization of a PV/wind hybrid energy conversion system with battery storage using response surface methodology. Applied Energy, 85(2008), p. 1086-1101.

v. JLG, D., 1999. Wind speed simulation in wind farms for steady-state security assessment of electrical power systems. IEEE Trans Energy Convers, 14(4), p. 1582-1588.

vi. Kariniotakis, G., Stavrakakis, G. \& Nogaret, E., 1996. Wind power forecasting using advanced neural networks models. IEEE Trans Energy Convers, 11(4), p. 762-767.

vii. Kellogg, W., Nehrir, M., Venkataramanan, G. \& Gerez, V., 1998. Generation unit sizing and cost analysis for stand-alone wind, photovoltaic, and hybrid wind/pv systems. IEEE Trans on Energy Convers, 13(1), pp. 70-75.

viii. Li, S., Wunsch, D., O’Hair, E. \& Giesselmann, M., 2001. Comparative analysis of regression and artificial neural network models for wind turbine power curve estimation. $J$ Solar Energy Eng, 2001(123), p. 327-332..

ix. $\quad$ Nolde, K. \& Morar, M., 2010. Electrical load tracking scheduling of a steel plant. Computers and Chemical Engineering, 34(2010), p. 1899-1903.

x. Stoyanov, 2011. Etude de Différentes Structures de Systèmes Hybrides à Sources d'Energie Renouvelables', Thèse de Doctorat en Energétique, s.l.: Université Technique de Sofia.

xi. Stoyanov, L. \& Lazarov, G. N. e. V., 2007. Optimisation des Systèmes Multi-Sources de Production d’Electricité à Energies Renouvelables. Revue des Energies Renouvelables, 10(1), pp. 1-18.

xii. Strbac, G., 2008. Demand side management: benefits and challenges. Energy Policy, 36(12), pp. 4419-4426.

xiii. Wang, X., Palazoglu, A. \& El-Farra, N. H., 2015. Operational optimization and demand response of hybrid renewable energy systems. Applied Energy, 143(2015), pp. 324-335.

xiv. Yang, D. \& Chen, Y., 2009. Demand Response and Market Performance in Power Economics, Power \& Energy Society General Meeting. s.l., IEEE.

xv. Yang, H., Zhou, W. \& Lou, C., 2009. Optimal design and techno-economic analysis of a hybrid solar-wind power generation system. Appl. Energy, 86(2), p. 63-169.

xvi. Zelazo, D., Dai, R. \& Mesbahi, M., 2012. An energy management system for off-grid power systems. Energy Syst, 3(2012), pp. 153-179.

Asia Pacific Institute of Advanced Research (APIAR)

10.25275/apjcectv4i1ict6 